\title{
PATHWAYS TO PSYCHIATRIC CARE IN ETHIOPIA
}

Dr: YILMA YITAYEW BEKELE, MD, FCPsych (SA)

Dissertation submitted to the Department of Psychiatry and Mental Health, Faculty of Health Sciences, University of Cape Town, in partial fulfilment of the requirements of the degree of Master of Medicine (Psychiatry)

\section{Supervisors:}

Prof. Alan Tlisher, MBChB, MSe, MMed (Psych), PhD, FCPsych (SA), DCH Department of Psychiatry and Mental Health

University of Cape Town

South Africa

Dr. Atalay Alem, MD, pho

Department of psychiatry

Addis Ababa University

Ethiopis 
The copyright of this thesis vests in the author. No quotation from it or information derived from it is to be published without full acknowledgement of the source. The thesis is to be used for private study or noncommercial research purposes only.

Published by the University of Cape Town (UCT) in terms of the non-exclusive license granted to UCT by the author. 


\section{CONTENTS}

Acknowledgments .......................................................... I

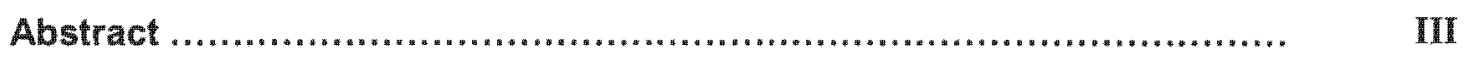

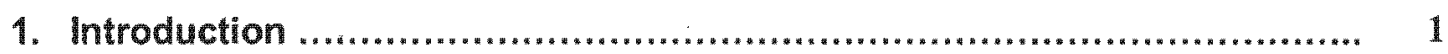

1.1. Background to Ethiopia .......................................................................

1.2. Mental Health service in Ethiopia ........................................................................

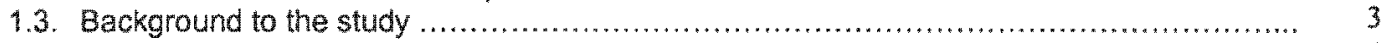

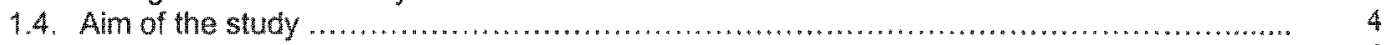

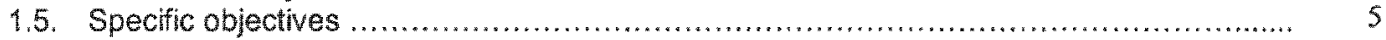

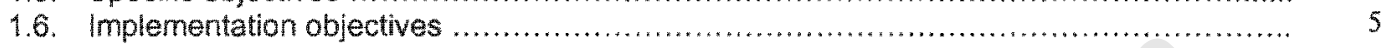

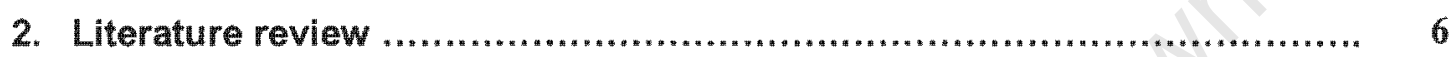

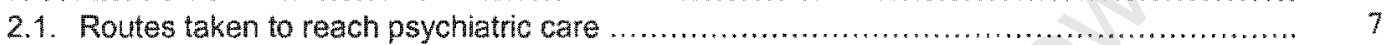

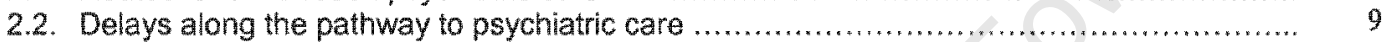

2.3. Factors associated with delays on the pathway to psychiatric care ............................. 11

3. Methods ............................................................................... 13

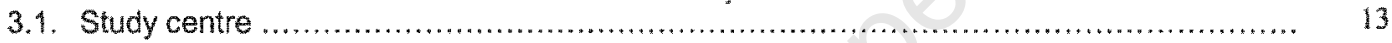

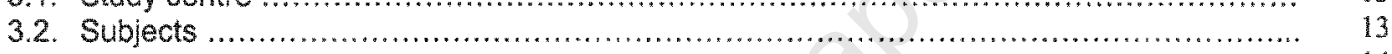

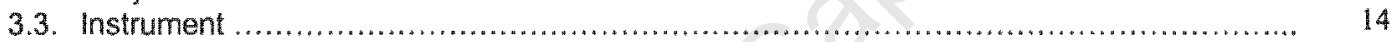

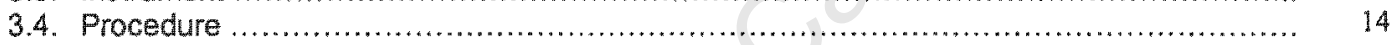

3.5. Data management and analysis ...................................................... 15

4. Results ...................................................................... 16

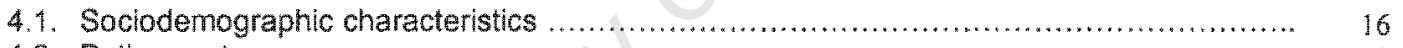

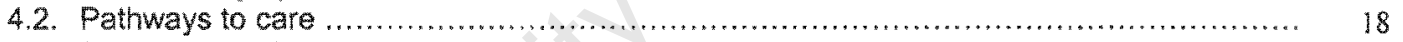

4.3. Delays along the pathway to care ............................................................. 19

4.3.1. Associations between delay and sociodemographic characteristics ................... 20

4.3.2. Associations between delay and types of first care providers .......................... 23

4.3.3. Associations between delay and main problem presented at the first carers ........ 24

4.3.4. Associations between delay and diagnosis made at the psychiatric service ......... 25

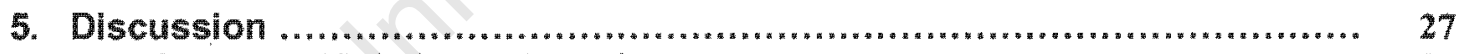

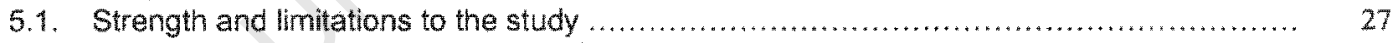

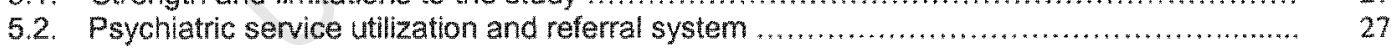

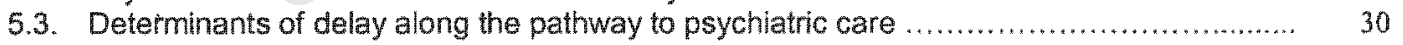

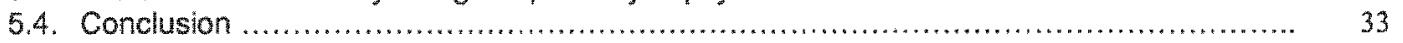

6. References .................................................................... 34

Appendix I. Encounter form: Pathways to care .................................... 37

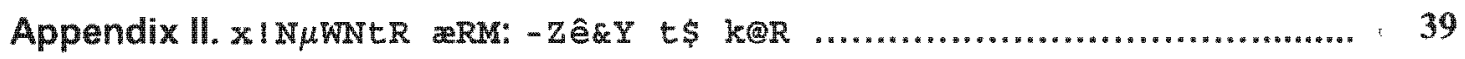




\section{ACKNOWLEDGMENTS}

My training would not have been possible without the generous financial support obtained from the World Health Organization and the Federal Ministry of Health of Ethiopia. I am also deeply indebted to the Department of Psychiatry and Mental Health, University of Cape Town, and the Schizophrenia and Bipolar Disorders Course and Outcome Study project of the Department of Psychiatry, Addis Ababa University, for financially supporting this research.

My deepest gratitude goes to all patients and their families who consented to participate in this research.

Professors Alan Flisher and Atalay Alem were supervisors of my clinical work as well as this research. I have been privileged to work under their outstanding supervision. I benefited from their extraordinary experience and guidance. They also helped me in obtaining a grant to conduct this research. I was first approached by Atalay to come and work with him at Amanuel Specialized Mental Hospital where he was the Medical Director 14 years ago, and to this day he remains a guide and inspiration to me. To both Alan and Atalay 1 owe tremendous debt of gratitude.

I would also like to express my special thanks to my friend and colleague Dr. Yonas Bahiretibeb for coordinating and supervising the data collection. He also cleaned the data, supervised data entry and assisted me in training the data collectors.

I also appreciate other colleagues and outstanding members of the following institutions for their support and sharing of experiences: the Department of Psychiatry and Mental Health, University of Cape Town; the Department of Psychiatry, Addis Ababa University; and Amanuel Specialized Mental Hospital. 
My deepest thanks also goes to the following data collectors: Adanech Hunde, Almaz Tesema, Belaynesh Andarge, Etetu Gebregzabher, Habte Birhanu, and Zewditu Berhe.

I give special thanks to Dr. Charlotte Hanlon for reading the entire manuscript, editing the English and providing invaluable commentary.

I wish to thank Sendenesh Tesfaye for typing the questionnaire. I am also very grateful to Shewangizew Alemu for data entry.

Finally my family has been a constant source of love, inspiration and encouragement to me. I appreciate the patience of our children, Michael and Kirubel, who have done without me while I was away from home for four years for postgraduate study at the University of Cape Town in South Africa. My greatest thanks are reserved for my wife, Emebet Alemu, who lovingly abided with and anchored me throughout my study. She took care of our home and our children with limitless patience. She was enthusiastic from the start about my making a career in psychiatry and has constantly encouraged me in all my professional activities, even when this has involved personal sacrifices on her part. Her and our children's love and support have made completion of this study possible. I have truly been blessed to have them in my life, and I thank them more than words can express. 


\begin{abstract}
Background: It is recognized that the pathways patients take en route to psychiatric services vary between countries and socio-cultural groups. Delay along the pathway to care is not a mere reflection of organization of health care and referral systems but also of availability and accessibility of services. Studies have shown associations between delay and various sociodemographic, clinical and service related factors. Understanding the pathway to psychiatric care, and recognition of delay points along the pathway, is a crucial step for the development of intervention programs geared at improving the provision of mental health care.
\end{abstract}

Aim: To describe the routes taken by patients to reach to psychiatric care in Ethiopia, and to investigate the factors that may contribute to delays on the pathway to care.

Method: Over a two month period, a total of 1044 patients starting new episodes of care at Amanuel Specialized Mental Hospital in Ethiopia were interviewed using the 'Encounter' form, a questionnaire specifically designed by the WHO for the study of pathways to psychiatric care.

Result: The psychiatric service is mainly utilized by male patients and those who live closer to the service. Out of the total sample, $41 \%$ of patients directly contacted the psychiatric service. The remaining patients took indirect routes, visiting up to four different carers before reaching the psychiatric service. Where initial care was not received in the formal psychiatric service, the pathway is dominated by visits to holy water and church. The median delay between onset of illness and consultation with the psychiatric service is 38 weeks. Delay before first seeking care at the psychiatric service is significantly longer than before first seeking care from any other modern or traditional health care services. 
The longest delays before arriving at the psychiatric service are associated with the initial care-seeking visit being to traditional healing services (particularly herbalists and witchcraft), a presenting complaint of fits or an altered level of consciousness, and having a diagnosis of epilepsy.

Conclusion: Our study has demonstrated that there is poor utilization of formal psychiatric services in Ethiopia, especially by patients who live far away from the service. Additionally, the delay before seeking care is found to be remarkably long. A significant majority of patients resort to traditional healing methods when they get ill. However, efficient referral system and working relationship does not exist between the psychiatric service and the various traditional and modern health care providers. In order to improve mental health service provision and reduce suffering of patients and families, policy must focus on decentralization and strengthening of the psychiatric service at primary and secondary health care levels, thereby bringing services closer to the community. Implementation of a robust referral system and establishment of strong collaboration with various traditional and modern health care providers at all levels, together with provision of ongoing training about early detection, management and referral of patients, will help to reduce undue delay and unnecessary suffering of patients. Importantly, raising awareness in the general public about issues of mental health and de-stigmatizing mental illness, by increasing acceptability of helpseeking, will help to remove barriers to effective mental health care. 


\section{INTRODUCTION}

\subsection{BACKGROUND TO ETHIOPIA}

Ethiopia, a republic in East Africa, is bounded on the Northeast by Eritrea and Djibouti, on the East and Southeast by Somalia, on the Southwest by Kenya, and on the West and Northwest by Sudan. It has an area of about 1,130,000 sq km. According to the 1994 census the population is 60 million, with a sex ratio of 101.3 males per 100 females. Out of the total population $45.4 \%$ are under the age of 15 years and $3.2 \%$ above the age of 64 years. About $86.3 \%$ of the population earn their living from the land, mainly as subsistence farmers. The major religions are Orthodox Christian and Islam constituting $50.6 \%$ and $32.8 \%$ of the total population respectively (CSA 1999).

Ethiopia is a multi-ethnic state with between 70 and 80 languages spoken in the country. The three main languages are Amharic, Oromifa and Tigrinya. Amharic is the official language of the country and has its own unique alphabet.

Ethiopia is among the poorest countries in Africa on the basis of Gross National Product (GNP) per capita, which was estimated at a mere US $\$ 120$ (Aredo 1993). The nation's economy remains heavily dependent on the earnings of the agricultural sector, which provides about $43 \%$ of Gross Domestic Product (GDP) and about $90 \%$ of the total export. The most important cash crop is coffee, which accounts for $62 \%$ of all exports, and is the most valuable foreign exchange earner. From the overall national budget, only $6.5 \%$ is allocated for health, and the per capita health expenditure is only USD1.2 (Aredo 1993).

Ethiopia as a country has an extremely poor health status which is largely attributable to potentially preventable infectious diseases and nutritional deficiencies (NHSDP, MOH). The Crude Death Rate (CDR) is estimated to be $14.8 / 1000$ and Infant Mortality Rate (IMR) is $105-128 / 1000$. Maternal Mortality Rate (MMR) is 500-700/100,000 live births. 
Life expectancy at birth is estimated at $47-54$ years. The health service delivery system is pyramidal in shape. Health centres and their satellite health posts form the broad base of the pyramid; whereas, district, regional and specialized hospitals form the second, third, and fourth levels of the health service delivery system respectively. There are a total of 1,175 health posts, 257 health centres and 89 hospitals in the country. This gives a health facility to population ratio of 1:218,015 for a health centre; and 1:615,712 for a hospital. There are 38,910 people per medical doctor and 13,770 per nurse. Basic health service coverage is about $48.5 \%$

\subsection{MENTAL HEALTH SERVICES IN ETHIOPIA}

Until 1987, psychiatric services were avallable only in the capital city, Addis Ababa at two sites: (a) Amanuel specialized mental Hospital and; (b) the Psychiatry Department outpatient clinic of the Medical Faculty, Addis Ababa University, which is located at St. Paul's hospital (Alem et al. 1995). Subsequently, services have been developed to the extent that they are provided at 35 psychiatric centres that are distributed throughout the country in regional and district hospitals. Generally, two psychiatric nurses provide mental health services at each psychiatric centre. There are 10 psychiatrists and 122 psychiatric nurses in the country. This gives a psychiatrist to population ratio of $1: 5,600,000$, and psychiatric nurse to population ratio of 1:459,016. All psychiatrists are based in Addis Ababa; therefore, patients travel several hundreds of kilometres from their homes to find treatment there. Local people often seek care from local healers, but there is no working relationship between them and mental health services in the country.

There is no systematic referral system for psychiatric patients in Ethiopia; patients can refer themselves directly to primary care clinic, general hospital, psychiatric clinics and psychiatric hospital. 
They can also be referred to modern psychiatric services directly from traditional treatment centres, primary care clinics and general hospitals.

\subsection{BACKGROUND TO THE STUDY}

It had long been known that the majority of people with mental illnesses documented in community surveys have not been seen within hospital mental health services (Goldberg \& Huxley 1980). This leads to the postulation that there is a filtering process at work between the community and the wards of the psychiatric hospitals, which is selectively permeable to those with more severe disorders.

In their pioneering work, Goldberg and Huxley (1980) described a model of pathway to psychiatric care that consists of five levels and four filters. According to this model, and assuming annual period prevalence of psychiatric disorders in the community being $260-315 / 1000$, only $230 / 1000$ people with mental disorder will attend primary care services, 101 will have their psychiatric disorders identified, 23 will be referred to specialist psychiatric services; and only 6 will be admitted to psychiatric beds. This model states that most psychiatric patients start by consulting their general practitioner and from there directly proceed to a mental health centre.

But it was also appreciated that other pathways may also be used; for instance, traditional healers are consulted as often as primary care professionals, especially in developing countries, and refer some cases directly to psychiatric services. In some countries patients refer themselves directly to mental health professionals, while others will be referred by longer and less direct pathways, perhaps involving multiple carers (Abiodun 1995; Gater et al. 1991; Klic et al. 1994; Pradhan et al. 2001; Reeler 1992; Rozali et al. 2000; Vazquez-Barquero et. al. 1993). 
The pathways that patients take are also likely to be influenced by several factors such as perception of health and diseases, help seeking behaviour, ability of care givers to detect psychiatric disorders, conventions governing referral, relationships that exist between mental health services and other sources of help and the availability/accessibility of mental health and other helping agencies (Gater et al. 1991). Therefore the filtering process and the pathways to psychiatric care may differ across countries and socio-cultural groups.

In the Ethiopian setting, health is defined as a state of equilibrium among the physiological, spiritual, cosmological, ecological, and social forces surrounding man (Vecchiato 1993). Traditionally, mental illness has been attributed to supernatural forces such as spirits which enter a person's body, or the shadow cast by an evil eye (Alem et al. 1993; Araya and Aboud 1993). Modern psychiatric services are also very scarce, inaccessible, and relatively expensive to the majority of the population. Therefore most people go to priests, magicians, sorcerers and traditional healers to seek treatment for mental illness (Alem et al. 1993; Araya \& Aboud 1993; Giel et al. 1968). Patients usually resort to modern mental health care service only after they tried and failed with all possible traditional treatments. It is also a common practice in Ethiopia to care for and provide support to the mentally ill by family members at home (Araya \& Aboud 1993). Hence it is hypothesised that the pathway to psychiatric care in Ethiopia will be different from the five level model that is postulated by Goldberg and Huxley to operate in Western settings.

\subsection{AIM OF THE STUDY}

To describe the routes taken by patients to reach psychiatric care in Ethiopia, and to investigate the factors that may contribute to delays on the pathway to care. 


\subsection{SPECIFIC OBJECTIVES}

1. To draw the routes taken by patients to reach psychiatric care.

2. To evaluate the relative interval to reach psychiatric care in relation to the different care providers who have referred the patients.

3. To investigate the relationship between delay on the pathway to care and socio-demographic factors.

4. To investigate the relationship between delay on the pathway to care and clinical factors such as diagnosis and presenting complaints.

\subsection{IMPLEMENTATION OBJECTIVES}

The result of this study will be used:

- To develop strategies so as to avoid unnecessary delay in the provision of mental health care.

- To organise the necessary program to train health staff in order to provide early and appropriate mental health care at the lowest possible level of health care,

- To develop a working relationship with traditional healers and other care providers working at different levels on the pathway to psychiatric care in Ethiopia. 


\section{LITERATURE REVIEW}

In many countries of the world doctors and other health professionals refer most patients to mental health services. This supports the notion of a filtering mechanism that operates between the community and the referring professional, as well as between that professional and the mental illness services.

Goldberg and Huxley (1980) described the pathway to psychiatric care as consisting of five levels and four filters. Level 1 represents the community; at this level our knowledge is derived from psychiatric morbidity in a population. Level 2 is represented by studies of psychiatric morbidity among patients attending primary care physicians, irrespective of whether or not the physician has detected the illness. Level 3 consists of those patients attending primary care physicians who are identified as "psychiatrically sick" by the doctor. These patients collectively represent psychiatric morbidity as it is seen from the vantage point of the primary care physician, and they will be referred to as the "conspicuous psychiatric morbidity" of general medical practice. Patients attending psychiatrists in outpatient clinics and private offices represent level 4 . Patients admitted to mental hospitals represent level 5.

The first filter is between the first and second levels. The factor which determines whether or not an individual passes through the first filter is often referred to as "illness behaviour" of the patient. The second filter is represented by their doctor's ability to detect psychiatric disorders among patients in the second level. The third filter represents referral to mental illness services. The fourth filter is represented by admission to psychiatric beds. Some psychiatric patients reach psychiatric services without passing through every filter en route. There is a considerable 'short circuit' of the second and third filters, in that a substantial number of patients are self referred and thus pass directly from the first filter to level 4 . 


\subsection{ROUTES TAKEN TO REACH PSYCHIATRIC CARE}

Gater et al. (1991) carried out a collaborative study on behalf of the WHO concerned with the pathways taken by patients on their way to care from mental health services in 11 countries. The study showed that pathways in countries which are well provided with mental health staff were dominated by General Practitioners (GPS) and to a lesser extent by hospital doctors. However less resourced centres like those in Pakistan, India, and Indonesia showed a wide variety of pathways with native or religious healers often playing an important part. The four European centres (England, Portugal, Spain and Czechoslovakia) as well as Cuba were the countries containing the better resourced centres, and these all showed a direct pathway from the community to primary care, and from there straight on to the mental illness services for between two third and four fifth of the patients, with most of the remainder coming from hospital doctors. In Spain, Portugal, Mexico, Pakistan and India, there were significant numbers of people seeing psychiatrists as their first port of call. In this study, it was also found out that patients in developing countries commonly seek help for mental health problems from traditional and religious healers.

In a similar study from South Manchester looking at 250 new referrals to mental health services, almost two thirds were found to be referred directly by their GPs while a further third were referred by hospital doctors. Non-medical sources of referral accounted for only $2 \%$ of new cases (Gater \& Goldberg 1991).

Vazquez-Barquero et al. (1993) in Cantabria (Spain) found that the majority of new patients established first contact with both general practitioners $(54 \%)$ and hospital doctors (26\%), and from there directly proceeded to psychiatric services. In fact, $84 \%$ of patients who reached psychiatric services have been referred to them from these sources. Direct referrals to psychiatric services were very few $(10 \%)$. In this study they also verified the existence of possible variations in the pathways taken by patients between urban and rural health areas. 
In a rural health area, the majority of newly referred patients established first contact with the general practitioner and to a lesser extent with hospital doctors and from there directly progressed to the psychiatric service. In urban area there was a greater tendency to directly contact specialised medical and psychiatric services.

The pathway in Ankara (Klic et al. 1994) is dominated by self referral of patients. Only $4 \%$ of patients contacted their GPs first, compared with $42 \%$ who first saw hospital doctors and $53 \%$ who contacted the psychiatric service directly.

In a survey conducted in Italy that involved 116 patients from South Verona community psychiatric service; $36 \%$ were self referrals, $34 \%$ were referred by GPs, $15 \%$ referred by Hospital doctors and $8 \%$ by other psychiatric services (Balestrieri et al. 1994).

Another study conducted in South Verona by Amaddeo et al. (2001) demonstrated that the most common route to mental health service was via a GP $(40 \%)$, followed by a referral from a hospital doctor $(26 \%)$. The third most common route was self-referral $(23 \%)$. Psychiatrists in private practice were responsible for a further $3 \%$ which means that referrals by doctors accounted for more than $70 \%$ of all new episodes.

In India, a study concerning first care givers that involved 384 respondents; $34.1 \%$ had chosen psychiatrists, $29.4 \%$ GPS and $26 \%$ had chosen faith healers and exorcists as their first care givers to their psychiatric problems (Pradhan et al. 2001)

Among 134 patients studied in Malay by Rozali et al. (2000),69\% had visited traditional healers (Bomoh) before consulting psychiatrists. The second popular choice of treatment was medical practitioners and only small percentage of them had consulted homeopathic practitioners and herbalists. 
An examination of the pathway to psychiatric care in Harare, Zimbabwe (Reeler 1992) revealed a picture different to that of the British pathway where the majority of patients will initially consult GP. The route to care indicated a bypass of primary care, and the use of psychiatric services as the initial point of entry to care for a significant number of patients.

A similar pathway study in Nigeria demonstrated that $26.5 \%$ of patients initially sought care from traditional healers, $13.4 \%$ had initial contact with religious healers, $55.9 \%$ presented to various medical practitioners in public and private health facilities and $4.2 \%$ made initial contact with patent medicine dealers when they became mentally ill (Abiodun 1995).

\subsection{DELAYS ALONG THE PATHWAY TO PSYCHIATRIC CARE}

Major delay points can be recognised at crucial spots along the pathway. There may be delay between the onset of the disorder and the initial contact with the helper, and subsequent delay between first contact with a helper and being referred to a mental health professional. Delay can also be encountered while waiting to see a mental health professional or to get admission to hospital. It is within this context that we can consider the various approaches that may be required to address the blocks or inefficiencies in the pathway. Therefore, analysis of delays along the pathways that patients take in pursuit of mental health treatment is relevant for learning about the functioning of services and for improving their provision of care. This is so, as delays appear to be to a certain extent a reflection not only of conventions governing referrals but also of the availability and accessibility of services.

In a cross-cultural study, Gater et al. (1991) found the median delay between first developing symptoms and seeking care to vary greatly between centres, ranging from 1 to 32 weeks. 
However the delays between first seeking care and arriving at the mental health professional were remarkably short, with medians of less than 5 weeks at almost all centres. In this study, the delays following being seen by primary care physicians were shorter in all centres and the delay after seeing hospital doctors were even shorter. But, there was evidence that those passing through native healers have experienced longer delays. Additionally it was noted that native healers are often associated with recursive pathways, meaning that patients go back and forwards between care providers and perhaps referred to mental health services as a last resort.

In the South Manchester study (Gater \& Goldberg 1991), the median interval between onset of mental health problems and first seeking care for all patients was 10 weeks. However; patients who presented to an accident and emergency department tended to have the shortest time before they sought care, while patients who went first to their GP had experienced their symptoms for a longer period. Once in care, patients moved to the psychiatric service after a median interval of only 4 weeks. General practitioners managed their patients for a median of 3 weeks before referring them to the psychiatric service, and there was on average a 2 weeks interval before patient was seen. Referral by hospital doctors usually occurred within a week but referral from accident and emergency department was immediate. This was due to the urgent nature of problems presenting to accident and emergency room where two-thirds presented with deliberate self-harm and were referred for urgent psychiatric assessment within a few days.

Kilic et al. (1994) demonstrated a median delay from the onset of the problem to arrival at the psychiatric services of 24 weeks in Ankara, Turkey. In this study the median delay between contacting a carer (GP or Hospital doctor) and reaching the Mental Health Practitioner was shown to be 1 week. The delay after seeing a religious healer was significantly longer than the delay after seeing a hospital doctor, GP or the police. 
In South Verona, Italy, Balestrieri et al. (1994) demonstrated that both the median interval between onset of the problem and first seeking care, and that between first seeking care and reaching mental health services was 8 weeks. Patients who arrived directly at the mental health services tended to have shorter delays when compared to those who arrived via other routes. Very few patients were referred by non-medical carers in this study.

In Cantabria, delay along the pathway to psychiatric care was remarkably short which was attributed to the efficient mental health services that are available (vazquez-barquero et al. 1993).

As is the case in most developing countries, in Nigeria traditional healers play a prominent role in the route taken by mentally ill patients to psychiatric care. This has often resulted in significant delays before patients present to the psychiatric clinic (Abiodun 1995). However, in Harare (Zimbabwe) a significant proportion of patients consult traditional healers but these consultations were not found to result in undue delays to receiving specialist mental health care (Reeler 1992). This study has rather demonstrated a trend towards the shortest delay being experienced on the traditional healer's route, a finding which does not support the frequently expressed view that traditional healers have an obtrusive effect on major disorders.

\subsection{FACTORS ASSOCIATED WITH DELAYS ON THE PATHWAY TO PSYCHIATRIC CARE}

Delays on the pathway to psychiatric care have been shown to be associated with various socio-demographic, clinical and service related factors (Abiodun 1995; Amaddeo et al. 2001; Balestrieri et al. 1994; Gater et al. 1991; Gater \& Goldberg 1991; Kilic et al. 1994; Lincoln and McGorry 1995; Vazquez-Baraquero et al. 1993). 
According to Gater and Goldberg (1991), among women, the presence of children at home was associated with a long total interval. Patients who were not employed sought care more quickly than their employed counterparts, and single, widowed or separated women had shorter intervals than women who lived with their husbands. However, no gender difference was noted in the interval between first seeking care and first contact with the psychiatric services.

In South Verona (Italy), socio-demographic characteristics of patients did not influence intervals on the pathway (Balestrieri et al 1994). In Cantabria (Spain), Vazquez-Barquero et al. (1993) found a significantly longer delay for women.

The intervals also vary considerably according to the problem presented to the first caregiver. As might be expected, the shortest delays were associated with the appearance of psychotic symptoms and self-harm, while illnesses presenting with Alcohol or drug related problems were associate with the longest interval. Once care had been sought, self-harm, psychotic symptoms and disturbed behaviours were associated with the shortest intervals to receiving psychiatric services, while somatic symptoms had the longest.

Earlier studies demonstrated the importance of studying the pathways of patients who reach mental health services; hence, strategies could be developed so as to avoid unnecessary delays in the provision of mental health care and also for organisation of the necessary programs to train health staff to provide early and appropriate mental health help at the lowest level of specialisation required. However; to my knowledge no study of the pathway taken by patients on their way to care from mental health services in Ethiopia has been carried out to date. 


\section{METHODS}

\subsection{STUDY CENTER}

The study was conducted at Amanuel Mental Hospital in Addis Ababa, Ethiopia. This hospital, which has a bed capacity of 330 , provides outpatient and inpatient services for the full range of psychiatric disorders for clients coming from all over the country. It is staffed by 5 psychiatrists, 29 psychiatry nurses, 1 psychologist and 1 social worker.

According to the Amanuel hospital statistical report 1998-1999, an average of 2,447 patients are seen monthly in the out patient clinics of Amanuel hospital, of which about 480 are new presentations. Long stay patients who have no other place to go to occupy some of the hospital beds. Due to bed shortages, severely ill patients are often put on a waiting list for one to two weeks until they get admitted.

To see a doctor, patients or relatives have to queue in the hospital yard as early as 5:30 a.m. However, because of shortages of staff and facilities not all patients might be seen the same day. The emergency room is open 24 hours a day and 7 days a week. Psychiatric emergencies are able to be assessed by a doctor at any time. The hospital has neither subspecialty services nor specialised wards. Therefore, children and adults stay in the same ward, and patients with different degrees of severity of iliness are kept together. However, men and women are separated.

\subsection{SUBJECTS}

All new patients who attended Amanuel hospital during a 2-month period (May and June, 2003), were included in the study. "New patients" are defined as those patients who had never previously sought any service from the hospital. 
All patients or the caretakers agreed that the patients could be interviewed, giving a participation rate of $100 \%$.

\subsection{INSTRUMENT}

The "encounter form" which was designed by the WHO for the study of pathways to psychiatric care was used in this study (Appendix 1). The encounter form contains basic questions, including place where the contact has taken place, source of referral, name and profession of the mental health practitioner who sees the patient and characteristics of the patient (age, sex, marital status, social position, past history of psychiatric care). It also includes the profession of each previous carer whom the patient was in contact with, along with the total duration of symptoms, length of time since the patient was first seen, the source of each referral, the main problem presented, the main treatment offered, the duration of patient's journey to the carer and diagnosis of the patient made by the mental health practitioner.

Additional sociodemographic variables such as address, religion, ethnic group, level of education, occupation and family size were included to the original encounter form. But two of the variables which are not applicable to our study were removed. They referred to the name of the participating centre and whether the patient lived in the survey area. The encounter form was translated from English into Amharic by the candidate and back-translated by other people (Appendix 2). It was also pre-tested on 20 patients at Amanuel hospital and no significant problems were encountered with its use.

\subsection{PROCEDURE}

Four interviewers were recruited amongst psychiatric nurses working at Amanuel hospital. An attempt was made to include those who speak the three main languages that are spoken in the country; therefore, participants who could not understand Amharic were interviewed in their own language. 
A one-day training course was given to the interviewers on the use of the encounter form by the candidate and another researcher. The training included role-play, and interview of patients.

Subjects were screened and interviewed in the out patient rooms before they saw a doctor. Before the interview, informed consent was obtained from all patients. In the case of minors and participants whose mental state was such that they could not give consent or provide information themselves, consent and information was obtained from their care givers or escorts. When necessary, information was also collected from the patient's medical notes.

\subsection{DATA MANAGEMENT AND ANALYSIS}

The data were checked for completeness and entered into a database using the Statistical Program for Social Sciences (SPSS), Version 11.0 for Windows. The sociodemographic characteristics of the study population were described.

The types of care sought by patients before they arrived at the psychiatric service and, the routes that each patient took to reach the psychiatric service were identified. Then the number of patients at each level of care was calculated and, the pathway diagram was drawn.

The time delay along the pathway to care was calculated and compared in relation to sociodemographic characteristics, presenting complaint of patients, and diagnostic groups. Statistical analysis of delay in the different groups was carried out using Mann-Whitney and Kruskal-Wallis tests. 


\section{RESULTS}

\subsection{SOCIODEMOGRAPHIC CHARACTERISTICS}

During the 2 month study period, a total of 1,044 patients started a new episode of care with Amanuel specialized Mental Hospital. The sociodemographic characteristics of the study group are shown in Table 1.

Six hundred forty nine $(62.2 \%)$ patients were male. The mean age was 29 years (range $=2-85$ years; standard deviation $=13$ years). Five hundred sixty one $(53.7 \%)$ patients were single, four hundred five $(38.8 \%)$ were married and the rest were separated, divorced or widowed. Four hundred sixty six $(44.6 \%)$ patients came from family sizes of between four and six persons. Three hundred seventy nine $(36.3 \%)$ were illiterate, three hundred forty three $(32.9 \%)$ attended primary school and the rest were educated up to secondary school or above. Two hundred nine (20\%) patients were jobless, one hundred ninety two (18.4\%) students, one hundred sixty four (15.7\%) farmers and one hundred thirty six $(13.0 \%)$ house wives.

Out of the total sample, $96.1 \%$ of patients had come from only four of the regional administrations in the country namely Addis Ababa (44.1\%), Oromia $(29.7 \%)$, Southern peoples region (14.9\%), and Amhara (7.4\%); and the rest $3.9 \%$ came from the remaining 5 regional administrations of the country.

Three hundred fifty one patients (33.6\%) belonged to the Oromo ethnic group, whereas three hundred $(28.7 \%)$ and two hundred thirty eight $(22.8 \%)$ patients belonged to Amhara and Gurage ethnic groups respectively. Five hundred ninety eight $(57.3 \%)$ patients belonged to the Ethiopian orthodox Christian faith and three hundred fifty one $(33.6 \%)$ were Muslims. 
Table 1: SOCIODEMOGRAPHIC CHARACTERISTCS

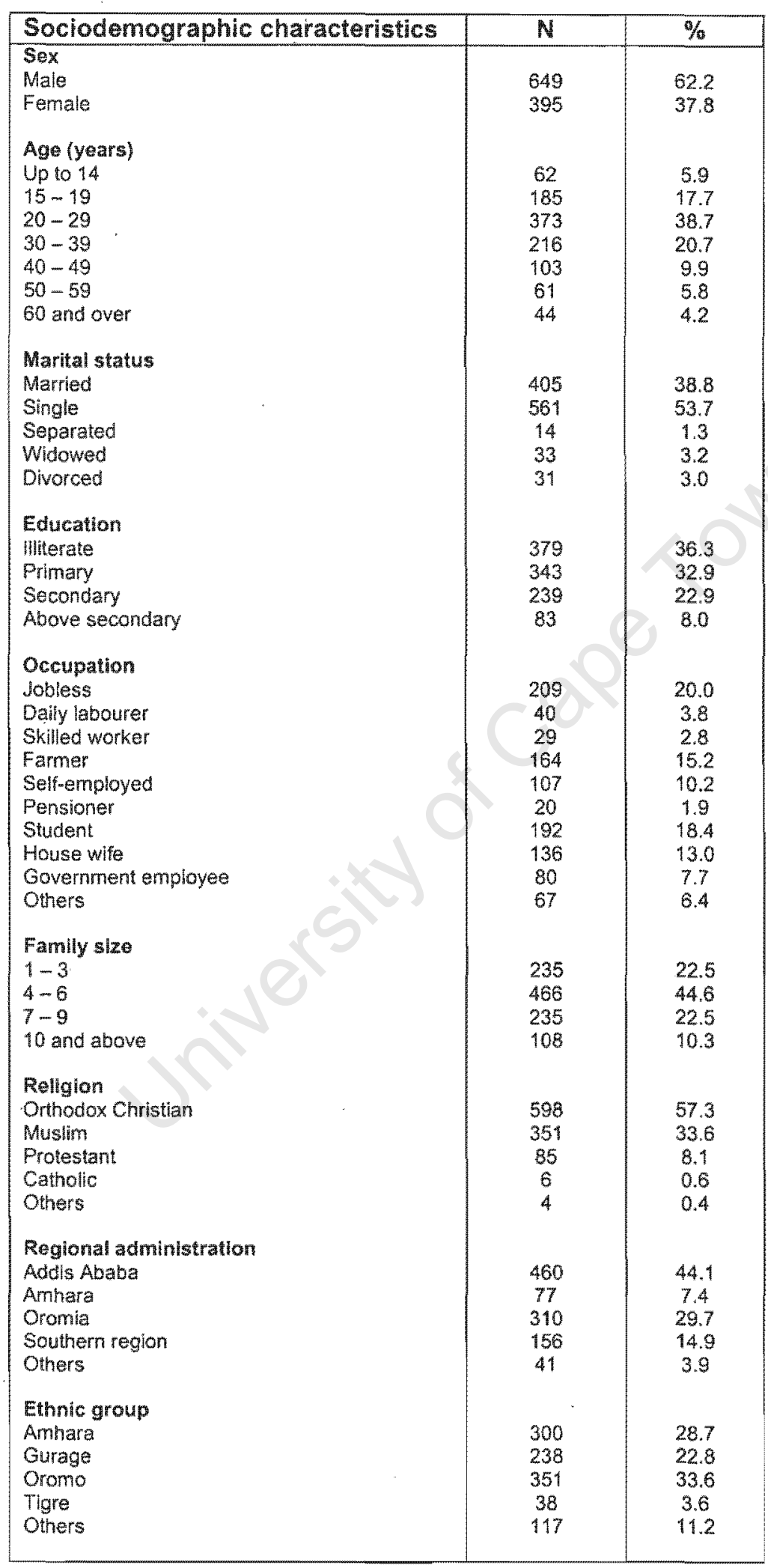


The majority ( $69.6 \%)$ of patients attended the psychiatric service on the advice of their family members, whereas $10.8 \%$ of patients decided to contact the psychiatric service by themselves, and $9.4 \%$ did so on the advice of patients who had previously utilised the psychiatric service. $87.6 \%$ of patients came to the psychiatric service without any referral letter form their previous carer.

\subsection{PATHWAYS TO CARE}

The routes that patients followed to reach the psychiatric service at Amanuel Specialized Mental Hospital are shown in Figure 1.

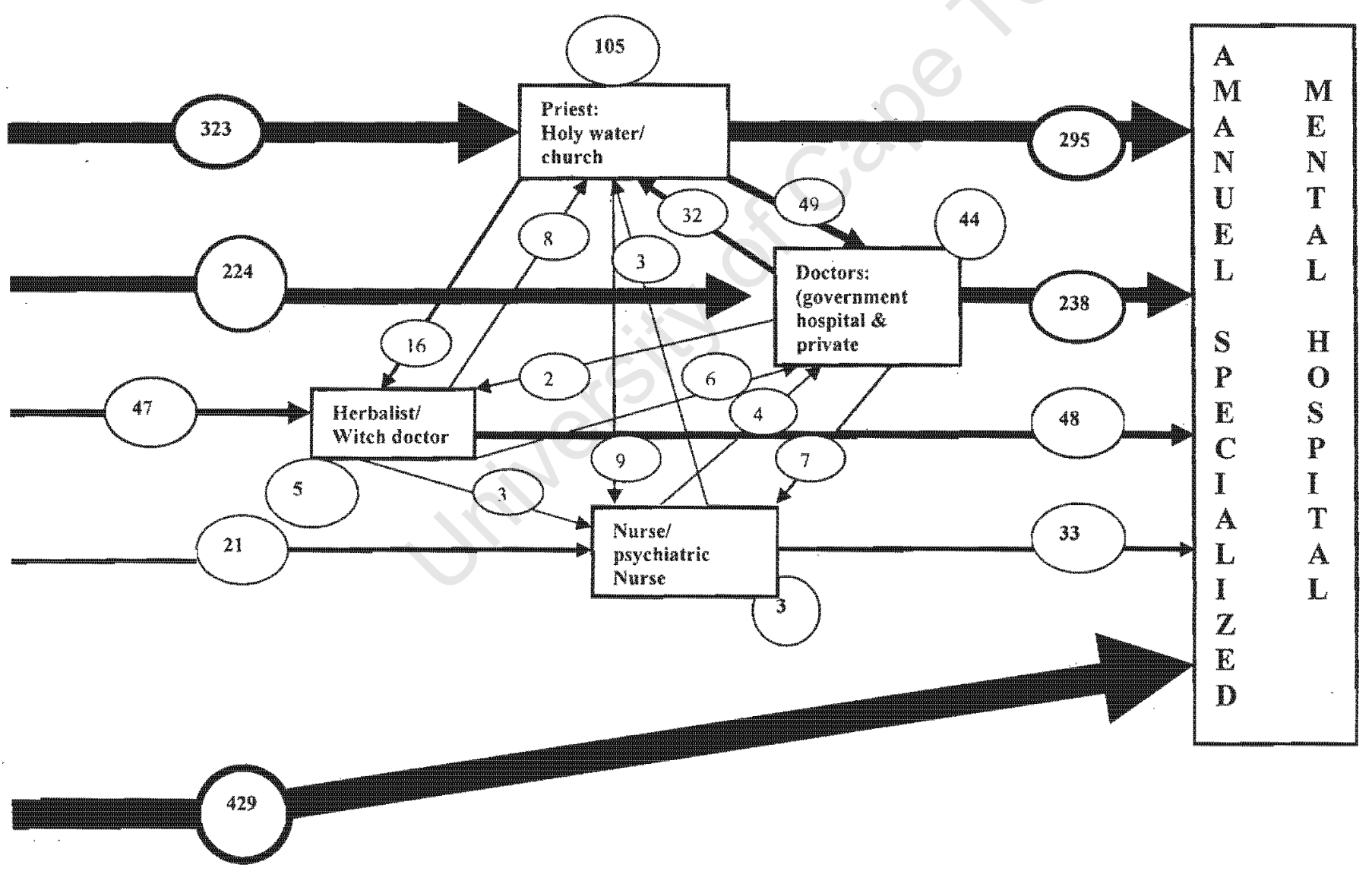

Fiqure 1. Pathway diagram that shows the route taken by 1044 patients to arrive at Amanuel Specialized mental Hospital, Ethiopia. The figures in the circle represent number of patients taking each step in the pathway. 
Out of the total 1044 sample of patients, four hundred and twenty nine $(41.1 \%)$ patients initially went directly to the psychiatric service without having previously sought help elsewhere, $30.9 \%$ sought help from holy water or church, $21.5 \%$ consulted doctors in private or government hospitals, $4.5 \%$ had initial contact with herbalists or witch doctors, and $2 \%$ were seen by nurses or psychiatric nurse.

After their first contact with a non-psychiatric care provider, $390(63.4 \%)$ of the remaining 615 patients subsequently went to the psychiatric service, $115(18.7 \%)$ sought help from holy water or church, $74(12 \%)$ visited doctors, 17 (2.8\%) visited nurses or Psychiatric nurses, and 19 (3.1\%) presented to herbalists or witch doctors.

At the third stage, $160(71.4 \%)$ of 224 patients visited the psychiatric service, 32 $(14.3 \%)$ sought help from holy water or church, $25(11.2 \%)$ consulted doctors, 3 (1.3\%) consulted nurses or Psychiatric nurses, and $4(1.7 \%)$ had contact with witch doctors or Herbalists.

At the fourth stage, $55(84.6 \%)$ of the 65 patients subsequently went to the psychiatric service, $4(6.2 \%)$ consulted doctors, another $4(6.2 \%)$ sought help at holy water or church and $2(3.1 \%)$ patients consulted nurses or Psychiatric nurses. The remaining 10 patients subsequently presented to the psychiatric service at the fifth stage. Recursive pathways were commonly seen, particularly with those patients who went to holy water, church and non-psychiatric doctors.

\subsection{DELAYS ALONG THE PATHWAY TO CARE}

The delay between first developing symptoms and arrival at the psychiatric service ranged from less than 1 week up to 45 years, with mean value of 118.4 weeks [Standard Deviation (SD) $=195.92]$, and Modal value of 104 weeks. 
The median time was 38 weeks, with a $25^{\text {th }}$ percentile of 8 and an interquartile range of 148 weeks. The distribution of delay was non-Gaussian and highly leftskewed. The measure of central tendency that was most appropriate for these data was the median, and non-parametric statistical tests such as the KruskalWallis and Mann-Whitney tests were used in analysis.

\subsubsection{ASSOCIATIONS BETWEEN DELAY AND SOCIODEMOGRAPHIC CHARACTERISTICS}

Delays associated with sociodemographic characteristics are shown in Table 2. There were no significant associations between the duration of delay on the pathway to care and gender, age group, marital status, family size and ethnic group ( $p>0.05)$.

Patients who came from Addis Ababa had a significantly shorter delay along the pathway to care only compared to those who came from the Southern regional states $(p<0.05)$. There was a non-significant difference in delay to care between Addis Ababa patients and those coming from Amhara and Oromia regional states ( $p>0.05$ ), except the shorter delay between first seeking care and arrival at the psychiatric service for patients from Addis Ababa when compared to those from Oromia regional states $(p=0.00)$. However, the delay of patients from Amhara, Oromia and southern people's regional states were similar to one another $(p>0.05)$. 
Table 2: Associations between median delays (weeks) and sociodemographic variables

\begin{tabular}{|c|c|c|c|c|c|c|c|c|c|c|c|c|}
\hline $\begin{array}{l}\text { Sociodemographic } \\
\text { characteristics }\end{array}$ & $\begin{array}{l}\text { Delay-1 } \\
\text { (weeks) }\end{array}$ & $x^{2}$ & df & $p^{*}$ & $\begin{array}{l}\text { Delay-2 } \\
\text { (weeks) }\end{array}$ & $x^{2}$ & df & $\mathrm{p}^{*}$ & $\begin{array}{l}\text { Delay-3 } \\
\text { (weeks) }\end{array}$ & $x^{2}$ & df & $p^{*}$ \\
\hline $\begin{array}{l}\text { Sez } \\
\text { Male } \\
\text { Female }\end{array}$ & $\begin{array}{l}12 \\
12\end{array}$ & 1.064 & 1 & 0.30 & $\begin{array}{l}32 \\
44\end{array}$ & 2.001 & 1 & 0.98 & $\begin{array}{l}12 \\
12\end{array}$ & 0.027 & 1 & 0.87 \\
\hline $\begin{array}{l}\text { Age } \\
\text { Up to } 14 \\
15-19 \\
20-29 \\
30-39 \\
40-49 \\
50-59 \\
60 \text { and over }\end{array}$ & $\begin{array}{l}27 \\
8 \\
12 \\
12 \\
20 \\
12 \\
22\end{array}$ & 6.914 & 6 & 0.33 & $\begin{array}{l}52 \\
52 \\
32 \\
28 \\
52 \\
32 \\
45\end{array}$ & 4.289 & 6 & 0.64 & $\begin{array}{l}28 \\
12 \\
12 \\
20 \\
14 \\
18 \\
9\end{array}$ & 9.279 & 6 & . \\
\hline $\begin{array}{l}\text { Marital status } \\
\text { Married } \\
\text { Single } \\
\text { Separated } \\
\text { Widowed } \\
\text { Divorced }\end{array}$ & $\begin{array}{l}12 \\
12 \\
3 \\
36 \\
15\end{array}$ & 4.698 & 4 & 0.32 & $\begin{array}{l}28 \\
52 \\
26 \\
104 \\
20\end{array}$ & 5.807 & 4 & 0.21 & $\begin{array}{l}12 \\
14 \\
16 \\
12 \\
34\end{array}$ & 0.631 & 4 & 0.96 \\
\hline $\begin{array}{l}\text { Education } \\
\text { Iliterate } \\
\text { Primary } \\
\text { Secondary } \\
\text { Above secondary }\end{array}$ & $\begin{array}{l}16 \\
15 \\
8 \\
8\end{array}$ & 7.838 & 3 & 0.05 & $\begin{array}{l}52 \\
52 \\
24 \\
12\end{array}$ & 10.769 & 3 & 0.01 & $\begin{array}{l}24 \\
12 \\
12 \\
12\end{array}$ & 7.141 & 3 & 0.07 \\
\hline $\begin{array}{l}\text { Occupation } \\
\text { Jobless } \\
\text { Dally labourer } \\
\text { Skilled worker } \\
\text { Farmer } \\
\text { Selfemployed } \\
\text { Pensioner } \\
\text { Student } \\
\text { House wife } \\
\text { Government employee } \\
\text { Others }\end{array}$ & $\begin{array}{l}24 \\
2 \\
2 \\
20 \\
10 \\
9 \\
8 \\
14 \\
9 \\
14\end{array}$ & 16.651 & 9 & 0.05 & $\begin{array}{l}60 \\
32 \\
16 \\
36 \\
28 \\
32 \\
32 \\
32 \\
24 \\
52\end{array}$ & 14.654 & 9 & 0.10 & $\begin{array}{l}30 \\
12 \\
4.5 \\
20 \\
12 \\
4.5 \\
11 \\
16 \\
12 \\
52\end{array}$ & & 9 & 0.02 \\
\hline
\end{tabular}




\begin{tabular}{|c|c|c|c|c|c|c|c|c|c|c|c|c|}
\hline $\begin{array}{l}\text { Family size } \\
1-3 \\
4-6 \\
7-9 \\
10 \text { and above }\end{array}$ & $\begin{array}{l}12 \\
14 \\
8 \\
27\end{array}$ & 7.312 & 3 & 0.06 & $\begin{array}{l}32 \\
52 \\
28 \\
61\end{array}$ & 6.777 & 3 & 0.08 & $\begin{array}{l}12 \\
12 \\
13 \\
12\end{array}$ & 1.806 & 3 & 0.59 \\
\hline $\begin{array}{l}\text { Religion } \\
\text { Orthodox Christian } \\
\text { Musilim } \\
\text { Protestant } \\
\text { Catholic } \\
\text { Others }\end{array}$ & $\begin{array}{l}10 \\
16 \\
8 \\
68 \\
206\end{array}$ & 9.809 & 4 & 0.04 & $\begin{array}{l}34 \\
36 \\
44 \\
76 \\
208\end{array}$ & 5.409 & 4 & 0.25 & $\begin{array}{l}12 \\
20 \\
24 \\
48 \\
1\end{array}$ & 13.248 & 4 & 0.01 \\
\hline $\begin{array}{l}\text { Regional } \\
\text { administration } \\
\text { Addis Ababa } \\
\text { Amhara } \\
\text { Oromia } \\
\text { Southern region } \\
\text { Others }\end{array}$ & $\begin{array}{l}9.5 \\
12 \\
16 \\
24 \\
4\end{array}$ & 12.616 & 4 & 0.01 & $\begin{array}{l}32 \\
52 \\
36 \\
52 \\
40\end{array}$ & 8.095 & 4 & 0.09 & $\begin{array}{l}10 \\
24 \\
20 \\
24 \\
24\end{array}$ & 15.121 & 4 & 0.00 \\
\hline $\begin{array}{l}\text { Ethnic group } \\
\text { Amhara } \\
\text { Gurage } \\
\text { Oromo } \\
\text { Tigre } \\
\text { Others }\end{array}$ & $\begin{array}{l}9.5 \\
20 \\
10 \\
15 \\
12 \\
\end{array}$ & 6.718 & 4 & 0.15 & $\begin{array}{l}37 \\
52 \\
32 \\
50 \\
32\end{array}$ & 2.406 & 4 & 0.66 & $\begin{array}{l}12 \\
12 \\
20 \\
12 \\
12\end{array}$ & 2.738 & 4 & 0.60 \\
\hline
\end{tabular}

Delay-1: Median delay (weeks) between first developing symptoms and first seeking care.

Delay-2: Median delay (weeks) between first developing symptom and arrival at the psychiatric service.

Delay-3: Median delay (weeks) between first seeking care and arrival at the psychiatric service.

* Significance tested using Mann-Whitney $U$ and Kruskal-Wallis $H$ tests 


\subsubsection{ASSOCIATIONS BETWEEN DELAY AND TYPES OF FIRST CARE PROVIDERS}

Patients who came directly to the psychiatric service had experienced their symptoms for a significantly longer period ( 16 weeks) before seeking care than those who first sought care from hospital doctors ( 8.5 weeks, $p=0.00$ ), priests at holy water or church ( 8 weeks, $p=0.00$ ), and nurses/psychiatric nurses ( 8 weeks, $p=0.05$ ).

Median delays before first seeking care were not significantly different among patients who presented to hospital doctors, priests at holy water/ church, nurses/ psychiatric nurses and herbalists/ witch doctors $\left(\chi^{2} 2=1.745, d f=3, p=0.63\right)$.

Where the first carer is not the psychiatric service, priests at holy water/ church, and doctors are the predominant first line carers on the pathway. They saw $52.5 \%$ and $36.4 \%$ of the patients respectively before they went on to consult psychiatric services.

Patients who were first seen by herbalists/witch doctors tended to take longer ( 24 weeks) to arrive at the psychiatric service than those who were first seen by a priest at holy water/church (16 weeks), doctors (12 weeks), and nurses/ psychiatric nurses ( 10 weeks): $\left(\chi^{2}=13.15, d f=3, p=0.00\right)$. Patients who were seen first by doctors progressed faster (median interval 12 weeks) to the psychiatric service than those who went first to holy water/church (median interval 16 weeks); $\chi^{2}=8.836, d f=1, p=0.003$.

There was no significant difference in median delay between first seeing doctor and nurse, and arrival at the psychiatric service; and between going to holy water/ church and seeing nurse, and arrival at the psychiatric service $(p>0.05)$ 


\subsubsection{ASSOCIATIONS BETWEEN DELAY AND MAIN PROBLEM PRESENTED AT THE FIRST CARER}

The great majority of patients presented to their first carer with disturbed/ psychotic symptoms, followed by seizure/altered level of consciousness, anxiety symptoms, somatic problems, sleep problems, mood symptoms and suicidal behaviour.

The median delay between first developing symptoms and direct arrival at the psychiatric service and arrival via other routes according to main problems presented to the first care provider is presented in Table 3. Generally, the delay varies significantly according to the problem presented to the first carer in that seizure/ altered level of consciousness had the longest median delay (53 and 120 weeks) in both direct referrals and arrivals at the psychiatric services via other routes respectively $(p<0.05)$.

Table 3: Median delay (weeks) between first onset of symptoms and arrival at the psychiatric services directly and via other routes Vs main problems presented to the first carer

\begin{tabular}{|c|c|c|c|c|c|c|}
\hline \multirow[t]{2}{*}{ Problems presented to the first carer } & \multicolumn{3}{|c|}{$\begin{array}{l}\text { Direct arrival at the } \\
\text { psychiatric service }\end{array}$} & \multicolumn{3}{|c|}{$\begin{array}{l}\text { Arrival at the psychiatric } \\
\text { service via other routes }\end{array}$} \\
\hline & $\mathbb{N}$ & $\%$ & $\begin{array}{c}\text { Delay } \\
\text { (weeks) }\end{array}$ & $\mathbb{N}$ & $\%$ & $\begin{array}{c}\text { Delay } \\
\text { (weeks) }\end{array}$ \\
\hline Anxiety symptoms & 33 & 7.7 & 12 & 75 & 12.2 & 52 \\
\hline Disturbed/psychotic behaviour & 258 & 60.4 & 10 & 334 & 54.4 & 44 \\
\hline Seizure/ altered level of consciousness & 76 & 17.8 & 53 & 115 & 18.7 & 120 \\
\hline Mood symptoms & 7 & 1.6 & 52 & 9 & 1.5 & 52 \\
\hline Sleep problem & 23 & 5.4 & 16 & 31 & 5.0 & 28 \\
\hline Somatic symptoms & 29 & 6.8 & 52 & 48 & 7.8 & 104 \\
\hline Suicidal behaviour" & 1 & 0.2 & 3 & 2 & 0.3 & 8 \\
\hline Total & 427 & 100 & & 614 & 100 & \\
\hline
\end{tabular}


However the delay for seizure/ altered level of consciousness (53 weeks) is not significantly longer than that of somatic symptoms (52 weeks) for patients who arrive directly to the psychiatric service $(p=0.18)$. The 3 and 8 weeks delay of suicidal behaviour for direct and non direct referrals respectively are not significantly shorter $(p>0.05)$ than any of the other presenting problems except seizure/ altered level of consciousness particularly for those patients who arrive at the psychiatric service via other routes.

\subsubsection{ASSOCIATIONS BETWEEN DELAY AND DIAGNOSIS MADE AT THE PSYCHIATRIC SERVICE}

At the psychiatric service; $42.5 \%$ of the study population received a diagnosis of Schizophrenia/ other psychotic disorders, 18.0\% Epilepsy, 16.0\% mood disorder, $10.1 \%$ Anxiety/ somatoform disorder, $6.3 \%$ physical problem, $2.9 \%$ cognitive disorder, $2.3 \%$ substance use disorders and $1.9 \%$ of the patients did not have their diagnosis confirmed. Overall delay (delay between first onset of symptoms and arrival at the psychiatric service) and delay between first seeking care and arrival at the psychiatric service vs. diagnosis is shown in Table -4 .

Epilepsy has the longest delay before arriving at the psychiatric service compared to all other diagnostic groups. But its delay does not amount to a statistically significant difference when it is compared to that of physical problems. In addition, the delay between first seeking care and arrival at the psychiatric service for epilepsy (52 weeks) is not significantly longer ( $p=0.11)$ than that of substance use disorders (8weeks). 
Table 4: Associations between median delays (weeks) and diagnosis made at the psychiatric service

\begin{tabular}{|c|c|c|c|c|c|c|}
\hline \multirow{2}{*}{ Diagnosis } & \multicolumn{3}{|c|}{$\begin{array}{l}\text { Median Delay between onset of } \\
\text { symptoms and arrival at the } \\
\text { psychiatric service }\end{array}$} & \multicolumn{3}{|c|}{$\begin{array}{l}\text { Median Delay between first seeking } \\
\text { care and arrival at the psychiatric } \\
\text { service }\end{array}$} \\
\hline & $\mathbf{N}$ & $\%$ & $\begin{array}{c}\text { Delay } \\
\text { (weeks) }\end{array}$ & $\mathrm{N}$ & $\%$ & $\begin{array}{c}\text { Delay } \\
\text { (weeks) }\end{array}$ \\
\hline Anxiety and somatoform disorders & 105 & 10.1 & 52 & 66 & 7.8 & 12 \\
\hline Cognitive disorders & 30 & 2.9 & 2 & 16 & 2.1 & 3 \\
\hline Diagnosis not confirmed & 20 & 1.9 & 6 & 10 & 2.8 & 32 \\
\hline Epllepsy & 188 & 18.0 & 104 & 117 & 25.4 & 52 \\
\hline Mood disorders & 167 & 16.0 & 24 & 98 & 15.3 & 12 \\
\hline Physical problem & 66 & 6.3 & 104 & 38 & 6.7 & 12 \\
\hline $\begin{array}{l}\text { Schizophrenia and other psychotic } \\
\text { disorders }\end{array}$ & 444 & 42.5 & 24 & 261 & 39.1 & 12 \\
\hline Substance use disorders & 24 & 2.3 & 30 & 9 & 0.7 & 8 \\
\hline
\end{tabular}

Patients with Cognitive disorders experienced the shortest overall delay along their pathway to the psychiatric service compared to all other diagnostic groups except Substance use disorders (for both overall delay and delay between first seeking care and arrival at the psychiatric service), mood disorders, and schizophrenia/ other psychotic disorders (for overall delay only) where the difference did not reach statistical significance $(p>0.05)$. 


\section{DISCUSSION}

\subsection{Strength and limitations to the study}

This study, which is the first of its kind in Ethiopia, has some strengths. It has a larger sample size than any previous studies of a similar nature. Also, it is the only study to involve patients coming from an entire country. The fact that the study was carried out in the only mental hospital that provides specialist psychiatric care for the entire country has created the opportunity for us to include such large number of patients who came from every part of the country.

However, there are limitations to this study. The first limitation is that we relied on patients' or care givers' retrospective recall of their symptoms, duration of illness, and the various care givers they visited before arriving at the psychiatric service, which might subject some of our data to recall bias. The second limitation could arise from social desirability bias i.e. patients might not truly acknowledge some of their previous source of care especially traditional healing practices such as witchcraft, because such practices might be considered unacceptable in certain social and religious settings. Therefore our finding of rate of visits to traditional healing practices could still be an underestimate of the true value. However the interviewers did their best to establish good rapport with patients and other informants in order to obtain reliable information as possible.

\subsection{Psychiatric Service Utilization and referral system}

The findings of this study have clearly demonstrated the absence of equitable tertiary psychiatric service utilization among patients who are coming from different parts of the country. The service is seen to be mainly utilized by patients who are coming from Addis Ababa in that they constituted almost a half of the total patients seen at the hospital during the study period. Patients from Tigrai, Afar, Somali, Benshangul-Gumez, Gambela and Harare regional states all combined represent only $3.9 \%$ of service users. 
The fact that patients from Addis Ababa are close to the service and the absence of psychiatric facility at primary and secondary health care level in Addis Ababa may be some of the reasons why they utilize the hospital service more than others. Alem et al. (1993), Araya and Aboud (1993), and Giel et al. (1968) have demonstrated that scarcity of psychiatric services in the country, problem of access and cost that is incurred for travelling hundreds of kilometres to reach the psychiatric service, and other expenses are some of the main reasons why the majority of the population do not utilize the psychiatric service. Therefore, strengthening the regional psychiatric services in material and manpower, thereby bringing the service down to the community level, must be given the utmost priority.

Despite the fact that sex ratio of the country's population is almost equal, psychiatric service utilization of females is found to be very low as compared to that of males in our study. This might be direct reflection of the difference in prevalence of some mental disorders such as schizophrenia between the two sexes (Kebede et al. 2003). The following factors could also be hypothesized in order to explain such gender difference in health service utilization: a) Men tends to be more violent and unmanageable in the community than women when they become psychotic; therefore, they are more likely to be seen at the psychiatric services. b) In a paternalistic society as in Ethiopia, where in most cases men are breadwinners of the household and women are economically dependant, the former may be the one who makes decision about health care seeking of the family. However, further study is essential to determine the reason for gender difference in psychiatric service utilization.

According to the Amanuel hospital statistical report (1998 - 1999) and the findings of this study, the mental hospital is daily seen to be overcrowded by all kinds of patients including patients with physical problems and others whose problem could be managed at primary or secondary health care level. 
Because of a lack of proper referral pathway and the presence of a substantial number of patients bypassing lower levels of care, the hospital is sometimes obliged to play the role of screening, referring and occasionally treating patients with physical problems. The risk of such kind of service delivery is twofold. Firstly, non-psychiatric patients might not receive appropriate investigation and treatment from a hospital designated for specialized psychiatric care. Secondly, the hospital will fail to meet its role as tertiary psychiatric care facility for the entire country.

This study has also clearly shown that there is no working relationship or proper referral system between the psychiatric service and other modern or traditional health practitioners in that only $1 / 10$ of patients came to the psychiatric service with a referral from their previous carer, whereas more than $2 / 3$ of patients did so on the advice of a family member. The fact that family members are playing a very big role in making decisions about the type of practitioner patients should consult when they become mentally ill was also documented in a similar study (Abiodun 1995). Therefore, this should be taken into account for awarenessraising initiatives.

The pathway in our study is dominated by direct referral which is similar to that of Rawalpindi and Bangalore in the multi-centre study by Gater et al. (1991) and that of Ankara by Kilic et al. (1994). Recursive pathways whereby patients visit the same kind of carer two or more times is also a common phenomenon in our study, particularly with patients who visited Holy- water/ church and doctors. This finding is similar to previous studies from other developing countries such as Ujung Pandang (Gater et al. 1991), Malay (Razali et al. 2000); and Nigeria (Abiodun 1995).

Where the first contact is not with the psychiatric services, native or religious healers played the biggest role as the fist port of call over doctors or any other modern health care providers in our study. 
Seeking care from traditional healers such as priests, herbalists and witchcraft for mental illness is a reflection of the prevailing belief among Ethiopian population that mental illnesses are caused by supernatural forces (Alem et al. 1993; Araya \& Aboud 1993). It also reflects the fact that native and religious healing services are more accessible, acceptable and affordable than modern treatment for great majority of the population (Alem et al. 1993; Araya \& Aboud 1993; Giel et al. 1968). Hence people resort to traditional way of treatment, and only consider modern psychiatric treatment after they exhaust all other possible alternatives.

Contrary to the expectation that Psychiatric nurses will serve a liaison between regional hospitals and the psychiatric service, they appeared to play very little role on this pathway study. This could either be due to the fact that they are capable of handling most of the cases by themselves and that they did not need to refer patients, or it could be the result of information bias in the data collection process as patients might not be able to properly identify and report the type of health professionals they saw in hospitals and clinics. However, further study is necessary to substantiate this finding.

\subsection{Determinants of delay along the pathway to psychiatric care}

In a previous study, it was documented that patients living closer to psychiatric services experience shorter delays to care (Gater et al. 1991). But in our study; despite higher psychiatric service utilization among Addis Ababa patients, presentation to the psychiatric service was as late as for those coming from far regions. Therefore, in addition to issues of accessibility of the psychiatric service and cost, perhaps differing beliefs about cause and treatment of mental illness, help seeking behaviour, fear of stigma, acceptability of psychiatric service and lack of awareness of the existence of psychiatric service in the country could also be some of the factors contributing to delay in help seeking. 
This may also be a factor in the huge difference observed in service utilization among regions. However, further study is required to substantiate the effect of these and other possible factors on psychiatric service utilization and delay of help seeking.

Unlike the findings of Gater and Goldberg (1991); Kilic et al. (1994); VazquezBarquero, et al. (1993) that demonstrated age and sex of patients affecting delay on the pathway to care, all sociodemographic characteristics except level of education did not significantly affect the delay between onset of symptoms and arrival at the psychiatric services in our study.

Contrary to the findings from a previous study in South Verona by Amadeo et al. (2001), delay before directly contacting the psychiatric service is longer than delay before first seeking care with any other type of traditional or modern health care professional in our study. The reason why patients, even those who are living close to the mental hospital take longer before they seek help from the psychiatric service than from other professionals should be a focus of future studies.

A significant majority of patients in our study sought help from native or religious healers for their psychiatric problems; nevertheless, patients who had first contact with these healers, particularly with Herbalist/ witchcraft appeared to take longer before they arrived at the psychiatric service than those who went first to see doctors or nurses. These findings were also confirmed by previous similar studies (Abiodun 1995, Gater et al. 1991, Kilic et al. 1994). But, contrary to the findings of our study and the commonly expressed view that visits to traditional healers are associated with longer delay, Reeler (1992) demonstrated that consultation with traditional healers is associated with the shortest delay before receiving specialist mental health care in Zimbabwe. 
Our study also showed that there is no proper referral system between the psychiatric service and doctors and nurses who are practicing in the general medical setting. It is also noted that patients who visited doctors and nurses also spent a very long time before they reached the psychiatric service. Our findings support previous reports that the majority of psychiatric disorders were unrecognised by general health workers and did not get appropriate treatment or referral to psychiatric services (Sartorius et al. 1993, Al Jaddu \& Malkawi 1997, Benjamin et al. 1992, Shiber et al. 1990, Harding et al. 1980). The problem of non-recognition or late diagnosis of these conditions could lead to considerable unnecessary expenditure, iatrogenic disease, disability and much dissatisfaction in health service users and providers.

Unlike the findings of previous studies (Kilic et al. 1994, Vazquez-Baraquero et al. 1993) which demonstrated somatic problems to be the commonest form of presentation to the first carer, and contrary to the notion that somatic complaints are the commonest presentation of mental illness in developing countries (Goldberg \& Huxley 1980); disturbed/ psychotic behaviour and seizure/ altered level of consciousness are found to be the two most common presentations in our study. Like wise the commonest diagnosis made at the psychiatric service in our study are Schizophrenia/ other psychotic disorders and Epilepsy.

Patients who presented to their first carer with problems of seizure/altered level of consciousness, and who subsequently received the diagnosis of epilepsy at the psychiatric service are the ones who experienced the longest delay along the pathway to care. The deep seated cultural belief among most Ethiopians that epilepsy, and for that matter any kind of mental illness, is caused by evil spirits or some form of supernatural force could be one of the major barriers for seeking early psychiatric treatment. The diagnostic category of cognitive disorders included delirium, which could be one of the reasons why cognitive disorder was associated with the short delay in our study. 


\subsection{Conclusion}

Our findings indicate that decentralization and strengthening of the psychiatric services at primary and secondary health care levels, and developing appropriate referral system will be crucial steps forward in order to provide effective mental health care service in the country. As the highest referral centre, Amanuel Mental Hospital should be reserved for treatment of patients that cannot be handled at primary and secondary care levels. Besides treatment of patients, the hospital should focus on other services such as training, research, as well as support, supervision and consultation for primary and secondary level of health care.

It is of paramount importance to establish strong working relationships with the various modern and traditional health care providers and regularly training them about early detection and referral of psychiatric patients who may require specialist care. This will reduce risk of disability and economic burden to the individual and the country especially by avoiding expenditure on non effective treatments. Most importantly, raising awareness of the general public about manifestations of common mental disorders and availability of modern psychiatric treatments, will shorten undue delay of treatment and unnecessary suffering of patients and their families.

This study, which will serve as an invaluable resource for mental health care planning and policy development in Ethiopia, will also generate a lot of ideas for further research. 


\section{REFERENCES}

1. Amanuel hospital statistical report. 1998-1999: Addis Ababa, Ethiopia.

2. Abiodun, O., Pathway to mental health care in Nigeria. Psychiatric Services, 1995. 46(8): p. 823-826.

3. Alem A, D.M., Araya M, Mental health in Ethiopia. Ethiopian Journal of Health Development, 1995. 9: p. 47-62.

4. Alem A, J.L., Argaw M, Traditional perceptions and treatment of mental disorders in central Ethiopia, in Year book of Cross-cultural Medicine and Psychopathology. 1993. p. 105-119.

5. Al-Jaddou H, M.A., Prevalence, recognition and management of mental disorders in primary health care in Northern Jordan. Acta Psychaitr Scand, 1997. 1: p. 3135.

6. Amaddeo F, Z.F., Tansella M, Thomicroft G, Accesibility and pathways to psychaitric care in a community based mental health system. Soc Psychiatry Psychiatr Epidemiol, 2001. 36(10): p. 500-507.

7. Araya M, A.F., Mental illness, in The Ecology of Health and Diseases in Ethiopia, K.H.a.Z. ZA, Editor. 1993, Boulder: West view press, Inc.

8. Aredo, D., The economy, with particular reference to the agricultural sector, in The Ecology of Health and Diseases in Ethiopia, K.H.a.Z. ZA, Editor. 1993, Boulder: West view press, Inc. p. 67-83.

9. Balestrieri M, B.M., Rodriguez-Sacristan A, Tansella M, pathways to psychaitric care in South Verona, Italy. Psychological Medicine, 1994. 24: p. 641-649.

10. CSA, The 1994 population and housing census of Ethiopia: Results of country level. 1999: Addis Ababa, Ethiopia.

11. Gater R, D.A.E.S.B., Barrientos G, Caraveo J et al., The pathways to psychiatric care: a cross-cultural study. Psychological Medicine, 1991. 21: p. 761-774.

12. Gater R, G.D., Pathways to psychaitric care in South Manchester. British Journal of Psychiatry, 1991. 159: p. 90-96.

13. Giel R, G.Y., Van Luijk JN, Psychiatric morbidity in 200 Ethiopian medical outpatients. Psychiat Neurol Neurochir, 1968. 71: p. 169-176. 
14. Giel R, G.Y., Van Luijk NN, Faith healing and spirit possession in Ghion, Ethiopia. Soc. Sci. and Med, 1968. 2: p. 63-79.

15. Giel R, V.L.J., Psychiatric morbidity in a small Ethiopian town. British Journal of Psychiatry, 1967. 115: p. 149-162.

16. Goldberg D, H.P., The pathways to psychaitric care, in Mental lllness in the Community. 1980, Tavistock: London.

17. Hailemariam A, K.H., Population, in The Ecology of Health and Disease in Ethiopia, K.H.a.Z. ZA, Editor. 1993, Boulder: West view Press, Inc. p. 47-66.

18. Harding TW, D.A.M., Baltazar j et al., Mental disorders in primary health care: a study of their frequency and diagnosisin four developing countries. Psychological Medicine, 1980. 10: p. 231-241.

19. Kilic C, R.M., Ustun TB, Gater R, pathways to psychaitric care in Ankara. Soc Psychiatry Psychaitr Epidemiol, 1994. 29: p. 131-136.

20. Kloos, H., The physical and biotic environment, in The Ecology of Health and Disease in Ethiopia, K.H.a.Z. ZA, Editor. 1993, Boulder: West view press, Inc. p. $29-45$.

21. Lincoln C, H.S., McGorry Pat D, Understanding the topography of the early psychosis pathways. British Journal of Psychiatry, 1998. 172 (suppl. 33): p. 21 25.

22. MOH, Federal MOH five year plan (1998-2002). NHSDP: Addis Ababa, Ethiopia.

23. Pradhan SC, S.M., Singh RA, Das J, Ram D et al., First care givers of mentally ill patients: a multi-centre study. Indian Journal of Medical Science, 2001. 55(4): p. 203-208.

24. Razali SM, N.M., Help-seeking pathways among Malay psychiatric patients. International Journal of Social Psychiatry, 2000 winter. 46(4): p. 281-289.

25. Reeler, A., Pathways to psychiatric care in Harare, Zimbabwe. Central African Joumal of Medicine, 1992. 38(1): p. 1-7. 
26. Sartorious N, U.B., Costa e Silvia JA, Goldberg D et al., An international study of psychological problems in primary care: Preliminary report from the World Health Organization collaborative project on "psychological problems in general health care". Archives of General Psychiatry, 1993. 50: p. 819-824.

27. Shiber A, M.B., Antonovsky H, Detection of emotional problems in the primary care clinic. Family Practice, 1990. 3: p. 195-200.

28. TGE, Health Policy of the Transitional Government of Ethiopia (TGE). 1993: Addis Ababa.

29. Vazquez-Baraquero JL, H.C.S., Artal JA et al., Pathways to psychaitric care in Cantabria. Acta Psychaitr Scand, 1993. 88: p. 229-234.

30. Vecchiato, N., Traditional medicine, in The Ecology of Health and Disease in Ethiopia, K.H.a.Z. ZA, Editor. 1993, Boulder: West view press, Inc. p. 157-178. 
Appendix I

ENCOUNTER FORM: PATIWWYS TO CARE

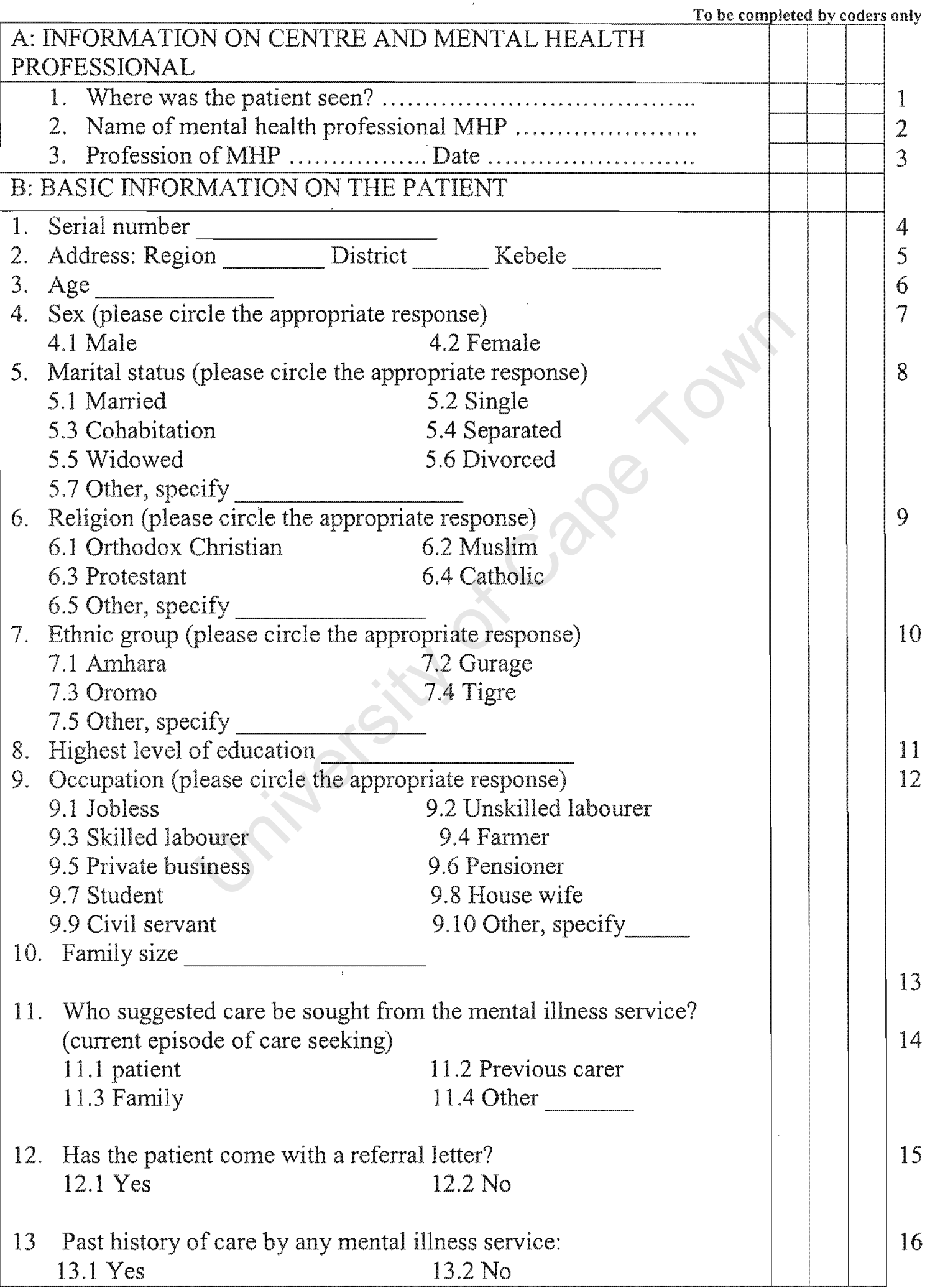




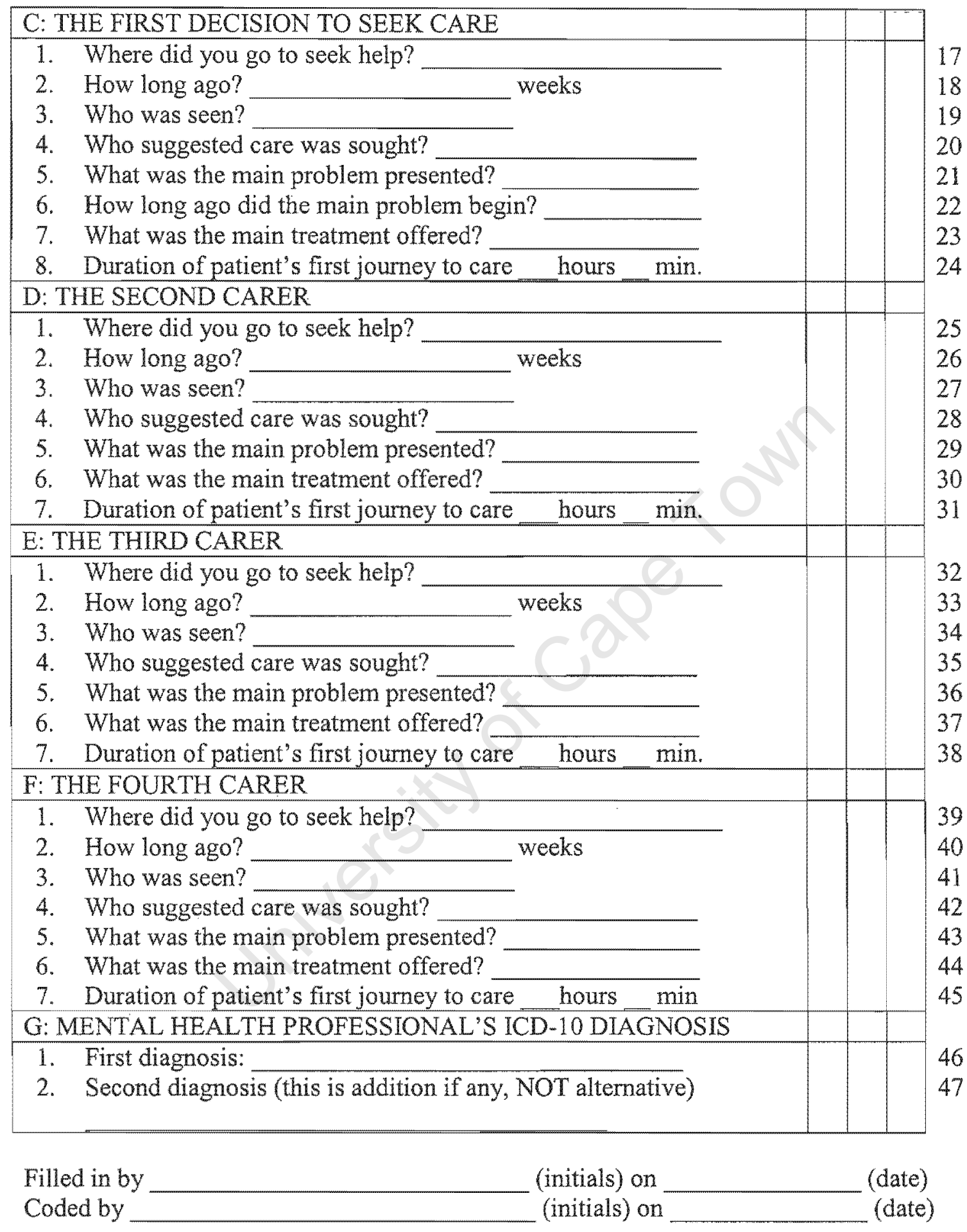

